\title{
O ESTADO DO CONHECIMENTO SOBRE OS RÉPTEIS MESOSSAUROS
}

Dina Celeste Araújo-Barberena (IG/UFRGS)

o conhecimento sobre os répteis mesossauros teve uma fase in cial, entre o final do século passado e começo deste, onde houve a divulgação das descobertas dos primeiros exemplares na América do Sul e Âfrica.

Uma segunda fase, comparativamente de pouco acréscimo, na qual os autores que referiam-se a estes répteis restringiram-se apenas à distintas interpretações quanto à taxonomia do grupo.

A terceira fase começa aproximadamente em meados da década de 60 e marca o início de uma série de trabalhos sobre o grupo, carac terizados pela análise integrada de evidências taxonômicas, paleoambientais e paleobiogeográficas.

o objetivo desta comunicação é o de oferecer uma sucinta versão do estado atual do conhecimento sobre estes répteis, na perspectiva dos trabalhos precedentes.

A primeira descricão de mesossauros, para a Bacia do Paraná, drta de 1886, quando COPE estudou material provindo da Formação Ira ti das localidades de Rio Claro, Limeira, Itapetininga e Tietê, classificando-o na espécie Stereosternum tumidum. Mac GREGOR (1908) 22 anos depois, descreveu Mesosaurus brasiliensis, baseado em espé cimes coletados no Estado do Paraná. O gênero Mesosaurus, represen tado por Mesosaurus tenuidens, já era conhecido da Àfrica do Sul, descrito por GERVAIS (1865). Novo gênero e nova espécie, Brasilosau ros sanpauloensis, são apresentados por SHIKAMA E OZAKI, em 1966, para a Bacia do Paraná. Esses dois autores japoneses receberam material coletado perto $(16 \mathrm{~km})$ da cidade de Tatui, Estado de São Paulo. As principais características genéricas diferenciais ba-seiam-se no crânio mais curto, comparado ao de Stereosternum e Meso saurus, maior número de vértebras cervicais (15) e costelas não pa quiostóticas.

Após a descrição de Stereosternum tumidum, as opiniões entre 
os pesquisadores dividiram-se em dois grupos. Existiam aqueles que consideravam stereosternum como um gênero distinto de Mesosaurus, podendo-se citar, entre estes, GEINITZ (1900), OSBORN (1903), BROOM (1904) e MENDES (1967). Outro grupo apontava a não validade genéri ca de Stereosternum, colocando-o na sinonimia de Mesosaurus. Dentro desta corrente, acham-se, por exemplo, SEELEY (1892), HUENE (1925), ROMER (1966) e KUHN (1969).

Os trabalhos posteriores a 1966, por sua vez, não fazem a minima referência à espécie Brazilosaurus sanpauloensis.

No início dos anos 70, contando com vários exemplares (79) de mesossaurus coletados na Bacia do paraná, tentamos delimitar, atra vés de estudo osteológico-estatistico, a validade ou não dos três gêneros nesta Bacia. Tanto a observação osteológica quanto o trata mento estatístico indicaram os três taxa como válidos. Estes resul tados foram publicados em 1976. Posteriormente LANDIM, PISANI e STURARO (1980) corroboraram os resultados por nós obtidos no Teste T, através de outra aproximação estatística ao problema.

Nesta época, na Africa do Sul, BURGER OELOFSEN completava seu estudo sobre os mesossauros da Bacia do Karoo, assunto de sua Tese de Doutorado, submetido em 1981. Detalhando a osteologia dos me sossauros o autor observou uma diferença entre os três gêneros, re ferente à morfologia dos arcos hemais. Mesosaurus, segundo o autor, apresenta estes arcos delgados, formando um "V" aberto, enquanto que, em Stereosternum e Brazilosaurus, são paquiostōticos e os bra cos dispõem-se em forma de "U". Esta diferença foi de suma importância para classificar esqueletos desarticulados.

Dos estudos efetuados nas duas bacias (Paraná e Karoo') surgi ram novas interpretações paleoecológicas, paleogeográficas e taxonômicas, expressas nos trabalhos de OELOFSEN e ARAOJO (1983 e 1987). No primeiro trabalho concluiu-se que as três formas (Mesosaurus, Stereosternum e Brazilosaurus) foram contemporâneas na época Irati e habitaram uma bacia única, porém em profundidades distintas.

Através das novas èvidências morfo-taxonômicas, associadas à observação de campo efetuada no afloramento Passo de São Borja(RS), OELOFSEN e ARAUJO (1983) constataram, ali, a presença dos três gêneros. Este fato permitiu reinterpretar as evidências apresentadas no trabalho de 1976, quanto à distribuição paleogeográfica destes pequenos répteis na Bacia do Paraná. Os autores vinculam esta distribuição aimplicações paleoecológicas: Mesosaurus, forma muito especializada à alimentação aquática, habitava águas mais profundas e, por isso, apresentava maior ocorrência nos folhelhos betuminosos. Stereosternum e Brazilosaurus ocupavam águas mais rasas e quentes e são, princinalmente, encontrados na facies calcária da Formação Irati.

Sob este novo enfoque considera-se o ar 
co de Ponta Grossa como a provável causa das águas rasas na região de São Paulo.

No trabalho de OELOFSEN e ARAUJO de 1987 registra-se a presença de Stereosternum na bacia do Karoo. Os exemplares provêm de sedi mentos que indicam regiões perto da linha de costa, confirmando as sim o mesmo hábito de águas rasas, descrito para forma brasileira. o estudo osteológico detalhado levou a considerar Mesosaurus bras $\underline{i}$ liensis na sinonimia de Mesosaurus tenuidens. O próprio Mc Gregor, já em 1908,teve dificuldade em separar o material brasileiro numa nova espécie. Para justificá-la, sua argumentação baseou-se apenas na distância geográfica, conclusão aceitável na época em que o mun do geocientifico não cogitava numa massa continental gonduânica.

Oelofsen e Araújo, no citado trabalho de 1987, propõem a hipótese espaço-temporal de que Mesosaurus tenuidens, Stereosternum tu midum e Brazilosaurus sanpauloensis colonizaram primeiro o mar Ira ti e daqui dispersaram para Āfrica. Esta afirmativa baseia-se nas seguintes observações do registro fóssil nos dois continentes: 1) os mesossauros encontram-se estratigraficamente mais baixos na Bacia do Paraná; 2) são comparativamente mais abundantes nesta bacia; 3) Brazilosaurus não foi encontrado, até o presente momento, na For mação Whitehill, indicando que esta forma não dispersou para Árica, fato que poderia ser explicado pela contestável menor adaptação desta espécie ao meio aquático.

Segundo OELOFSEN (1981), até o final do Permiano havia um"bra ço" de mar entre América do Sul e África. Este mar estendia-se pelas bacias Paraná, Huab, Kalahari e Karoo, compondo um am biente epicontinental de águas relativamente rasas. Os mesossosauros neste ambiente, constituem o primeiro registro de espécies de répteis (M. tenuidens e $S$. tumidum) idênticas, em distintos continentês de origem gonduânica.

Finalizando, Lavina, Araújo-Barberena, Faccini apresentam, no $\mathrm{X}$ Congresso Brasileiro de Paleontologia uma interpretação integrada, vinculando evidências sedimentológicas e paleontológicas obtidas do afloramento Passo de São Borja (RS). A associação de estruturas indicativas de ocorrência de grandes tempestades, com alta taxa de mortalidade de mesossauros, levaram a concluir que estes fe nômenos estão intimamente interligados. Postula-se que modificações nos parâmetros físico-químicos ambientais, introduzidas pelas tempestades seriam a causa da alta taxa de mortalidade dos mesôssauros verificada naquela localidade.

\section{REFERENCIAS BIBLIOGRÁFICAS}

ARAÚJO, D.F. 1976. Taxonomia e Relações dos Proganosauria da Bacia do Paraná. An. Acad. bras. Ci. 48(1):91-116. 
COPE, E.D. 1886. A Contribution to the Vertebrate Paleontology of Brazil. Proc. Amer. Phil. Soc., 23:7-15.

GERVAIS, M.P. 1864. Description de Mesosaurus tenuidens, reptile fossile de l'Afrique. Mem. Aead. Montpelzier Sec. Sci. p.169-75. LANDIM, P.M.B.; PISANI, J.F. e STURARO, J.R. 1980. Um Método para a representação Gráfica de Dados Multidimensionais em Geociências. In: CONGR. BRAS. GEOL., 31, Camboriú, SC., 1980. SBG. Anais... 2:1233-42.

MCGREGOR, J.H. 1908. On Mesosaurus brasiliensis nov. sp. from the Permian of Brazil. In: Comissão Estudos Minas de Carvão de Pedra do Brasiz. Ed. by I.C. White. National Press, Rio de Janeiro, Part. II:301-36.

MENDES, J.C. 1967. The Passo Dois Group (The Brazilian Portion of the Paraná Basin). In: BIGARELLA, J.J.; BECKER, R.D. \& PINTO, I. D. Problems in Brazilian Gondwana Geology. Curitiba, Paraná, p. 119-66.

OELOFSEN, B.W. 1981. An Anatomical and Systematic Study of the Family Mesosauridae (Reptilia; Proganosauria) with Special Reference to its Associated Fauna and Palaeoecological Environment in the Whitehill Sea. Thesis presented for the Degree of Doc-. tor Philosophy at the University of Stellenbosh, South Africa. OELOFSEN, B.W. \& ARAUUJ, D.C. 1983. Palaeoecology implications of the distribution of mesosaurid reptiles in the Permian Irati Sea (Parana Basin). South America. Rev. bras. Geoc. 13(1):1-6.

OELOFSEN, B.W. \& ARAÚJO, D.C. 1987. Two Mesosaurid reptiles (Mesosaurus tenuidens and Stereasternum tumidum) in Permian Gondwana of Southern Africa and South America. Jour. of Sei., Africa do Sul. $83(6): 370-2$.

SHIKAMA, T. OZAKI, H. 1966. On a reptilian skeleton from the Paleo zoic Formation of São Paulo, Brazil. Irans. Proc. Paleont. Soć. Jap. N.S., 64:351-58.

LAVINA, E.L.; ARAOJO-BARBERENA, D.C. \& FACCINI, U.F. 1989. OS Meso saurídeos da Formação Irati na Localidade de Passo são Borja, RS, : Evidências de uma Paleocatästrofe Ecológica? Abstract. In: CONGR. BRAS. PALEONT., 11, Curitiba, PR. p.35-36. 